\title{
Conservation, Creation, and Evolution: Revising the Darwinian Project
}

\author{
Gennady Shkliarevsky ${ }^{1, *}$
}

${ }^{1}$ Bard College

\begin{abstract}
There is hardly anything more central to our universe than conservation. Many scientific fields and disciplines view the law of conservation as one of the most fundamental universal laws. The Darwinian model pivots the process of evolution on variability, reproduction, and natural selection. Conservation plays a marginal role in this model and is not really universal, as the model allows exceptions to conservation, i.e. non-conservation, to play an equally important role in evolution. This anomalous role of conservation in the Darwinian model raises questions: What is the reason for this anomaly? Is conservation really universal, as we tend to believe or is it not, as the Darwinian model suggests? This contribution proposes a new model of evolution that focuses on levels of organization, rather than of species, organisms, or populations. It argues that conservation is central to evolution. Not only does this new model restores the universal status of conservation but it also makes possible to resolve some outstanding problems and controversies that continue to plague the Darwinian model. The article tries to advance the broad Darwinian project that seeks to explain the process of evolution as a product of the spontaneous processes in nature.
\end{abstract}

Corresponding author: Gennady Shkliarevsky, Bard College, Email: shkliare@bard.edu

Keywords: Conservation; evolution; the Darwinian project; the Darwinian model; the conservation anomaly; and levels of organization.

Received: Aug 06, 2019

Accepted: Sep 13, 2019

Published: Sep 25, 2019

Editor: George Eugene Mikhailovsky, CALIBRE, Global Mind Share. 


\section{Introduction}

\section{The Darwinian Project}

The publication of the book On the Origin of Species by Means of Natural Selection, or the Preservation of Favoured Races in the Struggle for Life by Charles Spencer Darwin in 1859 created an overnight sensation [1]. It marked the beginning of what has become one of the longest lasting intellectual projects in recent history. Its importance has not diminished as time has passed; it is as relevant today as it was over 150 years ago.

There is a good reason for this longevity. Darwin's project speaks directly to one of the most fundamental issues at the heart of our civilization: who we are and what our place is in the universe $[2, p .3]$. Humans are unique in comparison to the rest of nature. They are the only species that has consciousness and the capacity for rational thought. What is the source of these unique properties?

The religious tradition that has dominated our civilization for a very long time provided an unambiguous answer. The emergence of human race is an act of divine will. God has created humans. Since God and divine creation are inaccessible to human reason, humans cannot have a rational understanding of their origin. Faith is the only way to grasp the source of humanity. Sanctified by the religious tradition, this view of the origin of humanity was for a long time the only answer to the question of who we are and what our place is in the universe.

The rise of secular thought and science has dramatically changed the situation. Modern forms of knowledge challenged the dominance of religious doctrines. Yet despite many remarkable achievements the fundamental questions about our place in the universe remained unanswered. Even the new secular thinkers and scientists recognized that the problem may very well be in principle irresolvable due to fundamental differences in the nature of human thought and physical universe. Rene Descartes argued that reality consisted of two types of objects-"res cogitans" and "res extensa," or things that are thought and things that have extension. According to Descartes, these two types of objects constituted two separate realms that were dramatically different in their nature and largely incommensurable to each other [3]. Thought, Descartes contended, has no extension that is the fundamental property of the material world. The conclusion that followed from Descartes' argument was that thought and thinking could not in principal emerge from the world of nature.

Although Descartes' argument made perfect logical sense, the conclusion that followed form it created a great deal of discomfort among thinkers who came after Descartes. The argument implied that there were insurmountable limitations to human thought. The dualism proclaimed by Descartes posed a problem for a civilization that increasingly embraced the notion that its survival depended on rational understanding of reality. Darwin's theory opened the path to solving the problem created by Cartesian dualism.

The true significance of Darwin was not in discovering evolution. There were evolutionists before Darwin--representatives of the German Naturphilosophie, Jean-Baptiste Lamarck, Herbert Spencer, Robert Chambers, and others. They all saw nature as a dynamic system in the process of change and rejected the atomistic and mechanistic view of life world advocated by thinkers of the Enlightenment. However, they all believed that the course of the evolution from microorganisms to humans followed some preconceived plan. They also believed that the realization of this plan-its final goal-guided the evolution of life; and each stage in this evolution brought the plan closer to its realization.

The novelty that Darwin brought into evolutionary thinking was the idea that evolution had no plan and no goal. He argued that evolution was a result of the spontaneous forces and processes of nature and nothing else. There was much that was new and deeply disturbing in the Darwinian project that represented an attempt to bridge the gap between humanity and the rest of nature without a recourse to some preconceived plan or goal, either internal or external to nature. Also, the project foreshadowed a displacement of humanity from the privileged place in the universe assigned to it by the religious tradition-a view that had been widely accepted prior to Darwin, and not only among people of faith but also among non-believers. Finally, Darwin's project suggested that randomness, contingency, and 
chance were fundamental properties of nature and the universe- $a$ deeply disturbing idea that only gained currency almost one hundred years after Darwin.

In discussing the Darwinian project, one should make a distinction between the project and the theory of evolution that Darwin articulated in his book. Since its initial formulation by Darwin, the theory of evolution has undergone dramatic changes. It has been enriched by new findings and ideas. Its range has dramatically expanded far beyond biology. Perhaps the most dramatic change occurred in the 1930s and 1940s when the theory was reformulated to accommodate theoretical perspectives and empirical evidence from genetics, paleontology, and systematics. This result was the "modern synthesis," or what we often refer to today as the Standard Theory of Evolution (STE) [4, p. 163; also cf. 85]. Subsequently, the Darwinian theory has extended its reach well beyond biology, which led to the emergence of so-called Universal Darwinism that focuses on broad similarities between non-organic evolutionary processes and the Darwinian model of evolution [5].

There are several versions of the evolutionary theory today. The novel perspectives on evolution emphasize the role of epigenetic processes, phenotypes, niches and niche creation, genetic drift, developmental bias, plasticity, populations and groups rather than organisms or even species. They are as different from each other as they are from the original Darwinian formulation or even STE [2, pp. 6-8]. The new developments have even resulted in calls for adopting a new standard theory of evolution-the Extended Evolutionary Synthesis (EES) [4, 2]. Moreover, the extension of the Darwinian model to the process of evolution in non-organic spheres has led to a proliferation of competing evolutionary perspectives [6,7, 8, p. 243]. Alex Mesoudi, for example, contends that cultural studies have produced their own version of a "coherent evolutionary science of culture that is just as rigorous as evolutionary biology" [6, p. viii].

Despite their differences, however, all these versions share some basic features with Darwin's original formulation. As Kevin Laland has noted, "[t]he standard evolutionary theory (SET) largely retains the same assumptions as the original modern synthesis, which continues to channel how people think about evolution" [4, p. 162]. These basic features constitute what we may call the Darwinian model of the evolutionary process. Although originating in biology, the model has a wider application to all areas that experience evolutionary change. In his book on cultural evolution Alex Mesoudi, for example, notes that there is "a growing body of scientific research that is based on the fundamental premise that cultural change-by which I mean changes in socially transmitted beliefs, knowledge, technology, languages, social institutions, and so on-shares the very same principles that Darwin applied to biological change in The Origin a century and a half ago" $[6$, p. viii].

The Darwinian model includes three fundamental components: variation, replication, and natural selection [4, p. 162]. According to this model, initial variations are absolutely essential for the evolutionary process to take place. Without them the process simply cannot work. These variations are entirely haphazard-a product of spontaneous natural processes. They could be a result of flawed replication, random spontaneous mutations or mutations due to some entirely accidental external factors that affect genetic information. Some of these variations offer advantage, others less so or can even be disadvantageous and harmful to the organism.

Another important component of the Darwinian model is the mechanism that is capable of replicating these variations. Finally, there is the component that is most closely associated with Darwin's name and that he did a lot to popularize. It is the process of natural selection, or what Darwin called the "struggle for survival." This process weeds out those variations that offer no advantages or are even disadvantageous. These variations become extinct while variations that offer advantages survive. Such are the basic features of the Darwinian model that have not only survived to this day but dominate evolutionary studies in general, and not just in biology.

The Darwinian project has had an enormous impact on our civilization. Its influence has extended far beyond the confines of biology. Darwin popularized the idea of evolution and today evolutionary thinking has become a norm in many fields of knowledge and disciplines. Besides biology, the Darwinian model of 
evolution has had a profound effect on cosmology, psychology, social sciences, linguistics, and many other fields. Jiri Tanaka provides a good overview of the influence of the Darwinian model on many disciplines outside biology [9]. Due in large extent to the Darwinian project, we see evolution as characteristic of reality as a whole, not just nature and life; we have come to view reality in evolutionary terms. Indeed, we think of evolution as a truly universal process--one that is integral to our universe. We see constant evolutionary change as the essential condition without which the continued existence of our universe would be impossible.

Contradictions and Controversies in the Darwinian Model of Evolution

Despite the proliferation of new perspectives and approaches, there are hardly any rivals that challenge the domination of the Darwinian model, even though this model is not unproblematic. There are several important aspects of the Darwinian model that give rise to controversies and problems. This section will address some of the main ones that still remain unresolved.

\section{The Conservation Anomaly}

The connection we often make between evolution and the continued survival or our universe does not come as a surprise. After all, like evolution, conservation is also ubiquitous; we find it at all levels of organization in our universe. Conservation has its roots in the very unique nature of the universe. The universe is all there is. For all we know, it is a closed system. Nothing can come into it from outside because there is no outside; nothing can disappear from it because there is nowhere to disappear.

In its most basic formulation, the law of conservation states that the total energy of an isolated system remains constant. Energy can neither be created nor destroyed; it can only change its form. In classical physics conservation of energy is distinct from conservation of mass. Einstein's famous equation that relates mass to energy $E=m c^{2}$ has removed this distinction. Conservation also covers charge, spin, as well as linear and angular momentum, which pretty much extends conservation to all measurable physical quantities.
As one can see, there are many reasons to consider conservation universal. It originates in the unique nature of our universe-the fact that our universe is a closed system. It also manifests itself at all levels of organization of our universe-from physical to chemical, biological, etc. Examples of conservation abound. Exploding a stick of dynamite converts chemical energy into kinetic one; and the conversion of the energy of falling water into electricity is another good example of conservation in action. Conservation is ubiquitous. That is what makes conservation universal.

Like conservation, evolution is also universal and can be observed at all levels of organization in the universe. The fact that conservation and evolution are both universal suggests that the two must be connected. The Darwinian model also relates evolution to conservation. After all, biological evolution is about survival, and survival is a form of conservation.

As has already been mentioned, Darwin's innovation is not the idea of evolution, but rather the idea that evolution does not follow some prescriptive design. There are no supreme makers, no preconceived plans, and no final goals in the Darwinian model. Evolution is a product of spontaneous forces and processes that exist in nature. These forces and processes are blind. As such, they care nothing about which organism survives and which becomes extinct. They make no choices and have no preferences.

Darwin and his followers are very clear that "natural selection" is really a misnomer, a convenient phrase they use to explain what is happening in the course of evolution [10, 11, 12, 13]. Although contemporary practices of artificial selection influenced Darwin, there is nothing that resembles artificial selection in his theory. There is no actual selection involved, no selectionists who are in a position to select anything. The fact that one organism survives while another becomes extinct is merely a result of the "struggle for life" under conditions of limited resources-the process that eliminates those organisms that are unfit or poorly fit into the environment, leaving those that fit to live on.

At first glance the Darwinian model appears to be invincible and indisputable in its logic. On close analysis, however, it reveals a profound contradiction. 
Both evolution and conservation are universal, which suggests that they are equals. Universality allows no exceptions. Allowing no exceptions is the very meaning of the word "universal." Since both evolution and conservation are universal, they should allow no exceptions. Yet, in the Darwinian model some organisms survive, while others become extinct, which can only mean that conservation allows exceptions; and if that is so, then conservation is not universal. In other words, the Darwinian model does not treat conservation and evolution as equals. It reduces the role of conservation to that of an extra-a mere by-product of evolution.

The Darwinian model makes evolution appear as incomparable in its power. As the application of the Darwinian model expands to other fields of knowledge, evolution emerges as the primary and unrivaled process in the entire universe-indeed, the source of all; in fact, the only such source there is. Conservation appears to be a distant cousin of evolution-its mere consequence that depends on evolution.

The image of conservation that emerges from the Darwinian model is in sharp contrast with the view of conservation that is prevalent in other disciplines. In physics and chemistry, for example, the law of conservation is unquestionably one of the most important, if not the most important law in the universe. The treatment of conservation in the Darwinian model creates contradictions with other disciplines that also deal with both conservation and evolution and that view them largely as equals.

The way the Darwinian model treats conservation is very ambiguous. On one hand, the model emphasizes survival-that is, a form of conservation--as the sole consequence of evolution. Yet the role of conservation is purely subsidiary. It does not really do anything. Even non-conservation that in scientific circles hardly has a status equal to that of conservation seems to play a more prominent role than conservation; at least it does something by winnowing out unviable variations. Conservation merely follows as a consequence of this elimination. Tee Guidotti cogently summarized in his piece for American Scientists: "What Darwin called natural selection is simply this fact of elimination" [14]. Darwin's own description of natural selection emphatically stresses the role of non-conservation. In his discussion of natural selection at the beginning of chapter IV of his On the Origin of Species Darwin writes: "we may feel sure that any variation in the least degree injurious would be rigidly destroyed. This preservation of favourable variations and the rejection of injurious variations, I call Natural Selection" [1, p. 78]. The conflict in the way that science in general views conservation and the way that the Darwinian model treats it has led Jacques Monod, a prominent molecular biologist and a Nobel laureate, to draw a paradoxical conclusion. As he writes in his book Chance and Necessity, "For modern theory evolution is not a property of living beings, since it stems from the very imperfections of the conserving mechanism" [15, p. 116].

How can one reconcile the powerful image of conservation that we see in other disciplines with the weak role assigned to it in the Darwinian model of evolution-a role that is in no way equal to mighty evolution? There are only two possibilities that follow from this contradiction: either conservation is not universal or the Darwinian model is flawed.

There is not a single field of science that does not recognize the law of conservation as ubiquitous and universal. One cannot point to any scientific discipline, other than biology, that would assign an equal status to conservation and non-conservation. There is no universal law of non-conservation. Moreover, if in the case of conservation one can point to the unique nature of the universe as its source, there is no known source for non-conservation to which one can refer. Thus, the anomaly with regard to conservation creates tension between the Darwinian model and those fields of knowledge where conservation plays a central role.

Unlike theories, universals are hard to disprove. Indeed, history of human knowledge abounds in theories that had once been widely accepted and highly respected but were eventually superseded by more powerful rivals. The change was not due to a proof that the theory was wrong, just that it was not powerful enough. The rival simply offered more possibilities and included the old theory as its particular case-that is, case that was still valid under specific conditions or assumptions-thus conserving it. No one has abolished Euclidean geometry that still remains valid even though 
other more powerful theories of space have come into existence.

The fate of Ptolemy's geocentric theory is another good case in point. This theory had everything that a successful theory needed: logical consistency, observational verification, and a high degree of predictability. It had numerous practical applications that are still in use today, for example, in navigational systems. It did contain some anomalies related to translation in space, but these anomalies did not appear to be very significant and some additional hypotheses explained them quite well. By all standard, even contemporary ones, this theory was a total success. And yet, eventually another theory has superseded it.

The reason for change was not the rejection of the feature that was widely regarded as universal-the uniformity of translation in space-but rather in the affirmation of this principle and the formulation of a new theoretical approach based on the assumption that the Sun, not the Earth, was in the center of the universe and that celestial bodies moved around the Sun, rather than the Earth. The foundational premise of the Ptolemaic system has eventually been superseded by another and more powerful one-one that has offered more possibilities and included the geocentric theory as its particular case--that is, one that is valid under special conditions or assumptions.

The story of the geocentric theory is compelling. It tells us that success is not a sufficient criterion of validity. Even a very successful theory may still contain contradictions. Resolving these contradictions requires a revision of the model. The contradiction between the Darwinian model of evolution and the universality of conservation is hard to dismiss or explain away.

The Problem with Variability

Evolution is a form of movement. Static conditions of equilibrium cannot generate movement. Movement requires some initial instability, disequilibrium, or a low entropy state.

In the Darwinian model the process of evolution starts with initial variations that are a result of randomness or chance. Randomness thus plays an important role in the Darwinian model. James MacAllister summarizes it this way: "The Modern Synthesis toolbox holds only one tool: the mistake, the blind random mutation" [16]. According to Arkady Plotnitsky, "from Darwin on, chance is seen as an essential force in evolution, which gives the concept of chance a central role in the structure of evolutionary theory, especially as it is developed in Gould's work, including in this book [The Structure of Evolutionary Theory]" [17, paragraph $9,18]$.

However, randomness is not associated with low entropy; on the contrary, it is associated with high entropy and disorder [19]. The Darwinian model does not explain how a state of high entropy and disorder produces movement. It does not explain how the state of disequilibrium, or order, can result from one of equilibrium, or disorder. Moreover it does not even discuss the relationship between equilibrium/ randomness and disequilibrium/order.

There is also another problem related to variability. The Darwinian model asserts that randomness is the source of initial variations. This assertion may very well be true but there is no way of proving it. The assertion of randomness as a source of initial variations requires at minimum an a priori assumption that what occurs in a particular case is random. An a priori assumption is not a fact. In many ways, it is a premise that serves as the basis for constructing a theory. An a priori assumption has a probability of at least fifty per cent of being false. Its selection is an act of arbitrariness. In some sense, by constructing a model on the basis an arbitrary assumption one takes a chance with no guarantees.

Scientific methodology has only one solution for the problem that a priori assumptions pose: they should at least pass the test of rational justification. Rational justification does not prove that an assumption is right or wrong, but it does show that our assumption is not entirely arbitrary since it obeys the rules of logic and reason. It also shows that at least to some extent we control theory rather than theory controls us.

The simple fact is that there is absolutely no way to provide a rational justification for the existence of randomness or, for that matter, order, in any particular case. This is not to say that randomness and order do not exist. In fact, they may very well exist, but there is no way of proving their existence in specific cases. As many logicians, mathematicians, and computer 
scientists have convincingly argued, a set of numbers may show randomness, but there is no guarantee and no proof that if we extend this set indefinitely, it will not reveal some underlying order. Hans Primas, for example, shows that if axiomatic principle, such as determinism, cannot be satisfied, "it can be enforced by choosing a larger state space" [20]. Such enforcement, according to Primas, is perfectly compatible with mathematical probability theory because:

Every mathematically formulated dynamics of statistically reproducible events can be extended to a description in terms of a one-parameter group of automorphisms on an enlarged mathematical structure which describes a fictitious hidden determinism. Consequently, randomness in the sense of mathematical probability theory is only a weak generalization of determinism [20, p. 1$]$.

Jean Bricmont also sees ontic determinism lurking behind the appearance of quantum randomness [21, 22]. Even quantum randomness and uncertainty that have been a standard of modern view of physical reality since the original formulation of quantum theory in the 1930 s are no longer a certainty [23].

The Darwinian model can and does offer a proof that mutations exist. However, it does not and cannot prove that they are random. The lack of proof means in this case that there is at least a fifty per cent chance that initial variations may be a result of some underlying order, which would be an anathema to the Darwinian model. Again, this is not to say that initial variations are not random. This is to say, however, that there is no way of proving their randomness. The lack of justification means that we do not have rational control over theory, which effectively makes theory subjective and arbitrary. It is precisely the case when a possibility of theory controlling us is dangerously strong.

There are a growing number of biologists who dispute the critical assumption of randomness. Kevin Laland, for example, finds that "much variation is not random because developmental processes generate certain forms more readily than others" [4, 24]. Christian de Duve also offers an objection to randomness. In one of his widely publicized quotes that is all over the Internet, Christian de Duve, the author of $A$ Guided Tour of a Living Cell, opines:

If you equate the probability of the birth of a bacteria cell to chance assembly of its atoms, eternity will not suffice to produce one... Faced with the enormous sum of lucky draws behind the success of the evolutionary game, one may legitimately wonder to what extent this success is actually written into the fabric of the universe [25].

Paleontologist Simon Conway Morris feels the need for a research program that might reveal "a deeper fabric to biology in which Darwinian evolution remains central as the agency, but the nodes of occupation are effectively predetermined from the Big Bang" (26, pp. 309-310]. Again, this is not to argue against randomness or, for that matter, for it. This is simply to point out the intensity of the debate about randomness and the degree of disagreement even among biologists, which signals a lack of control over the theory.

One can sense this lack of control in inconsistencies of interpretations provided by the proponents of the Darwinian model. Although they regard variability that originates in random mutations as essential for evolution, they also display a persistent tendency to trace evolution to a common source-a progenitor [27]. Evolutionary biologists construct elaborate phylogenetic trees that originate in some common ancestor. Lynn Margulis points to this inconsistency when she criticizes "modelers of 'the tree of life'" who choose to ignore "alternative topologies" [28, p. 194]]. There was not much variability in primordial cells that looked pretty much alike; yet this fact did not prevent evolution from taking place. These heated debates illustrate the dissensions that the Darwinian model generates.

Since evolution is widely regarded as universal, we should be able to find a confirmation of the argument that variability is essential for evolution at spheres other than the biological one. Yet this is not the case. For example, the evolution that we observe in the microscopic world does not reveal any initial variability, either on the level of subatomic particles or on the atomic level. We do not find this confirmation on the molecular level either. Hydrogen is the most common element in our universe and all hydrogen molecules are alike. All other elements are a result of subsequent 
evolution; they are not a precondition for evolution on the molecular level. The simple fact is that low or even non-existent variability does not prevent evolution from taking place.

Finally, the claim that random variations are the source of evolutionary change has produced another controversy. The challenge comes from the proponents of Intelligent Design and creationism who argue that evolution resulting from random variations is statistically improbable, if not indeed impossible $[86,87,88]$. The response from the proponents of the Darwinian model has been forceful $[89,90]$. However, it has not been conclusive and is riddled with additional problems that will be discussed later.

\section{The Problem of Discontinuity}

There is another issue in the Darwinian model that remains unresolved. It is the issue of discontinuity. According to the Darwinian model, evolution occurs primarily as a continuous steady process of small incremental changes [29, p. 155]. Based on this view, the record of transition from one species to another should include a large number of transitional forms. However, there are very few such transitional forms found in geological or paleontological records.

This lack of evidence for transition posed back in the $19^{\text {th }}$ century and continues to pose now a serious problem for the proponents of the Darwinian model. Creationists, among others, point to the absence of evidence for transitional forms as their strongest argument in favor of creation and against evolution. Darwin was not unaware of this problem. In his On the Origin of Species he asks:

Why then is not every geological formation and every stratum full of such intermediate links? Geology assuredly does not reveal any such finely graduated organic chain; and this, perhaps is the gravest objection which can be urged against my theory [1, p. 246].

Darwin attributed this problem with evidence to the "extreme imperfection of the geological record" $[1$, p. 246]. As reasonable as this argument may be, it does not confront a deeper problem faced by the Darwinian model-the problem of discontinuity. The emergence of new species is not the only type of discontinuous phenomena that are so abundant in the history of evolution. The history of life on Earth provides evidence of major disruptions, leaps, and reversals. In addition to sudden explosions in variety and numbers of species, such as the Cambrian explosion of life forms, there were also dramatic mass extinctions of a large number of species-similar to the one that occurred at the end of the Cretaceous period that ended the reign of dinosaurs [30, 31, 32, 33, 34]. In addition to five big extinctions, fossil records reveal numerous extinction events at all scales. According to geophysicist David Jablonski, at least 95 percent of all species that have ever lived have become extinct. In a period of less than a million years-a very brief period in geological terms, the "Big Five" global extinctions eliminated over 50 percent of living species and made a huge impact on many different organisms [35]. (Hlodan 2007). It is hard to explain the events of this magnitude by contingent circumstances or chance. The Darwinian model obviously has some explaining to do, which would require confronting the general problem of discontinuity head on.

There have been several attempts by theorists of evolution to address this problem, some more successful than others. Willis Overton and Hayne Reese argue in their provocative article that the reason for the existence of the problem of discontinuity is primarily epistemological-that is, how we view reality, rather than what reality actually is. According to Overton and Reese, there are two basic ways of conceptualizing reality: constancy and change. If one recognizes constancy as ontologically primary, then one sees evolution as development in which effects are explained in terms of antecedent causes. The recognition of change as ontologically primary precludes such causal explanation. Change appears as an intrinsic property of reality, which precludes any causal explanation. Overton and Reese regard development (continuity) and change/ novelty (discontinuity) as two independent a priori principles that organize our knowledge. As a priori principles, they are incompatible with and incommensurable to each other. The best evidence each perspective will produce will be insufficient for their opponents. Thus, Overton and Reese conclude, "will the debate continue" [36, p. 120].

Peter Damerow has tried to explain the emergence of discontinuities in evolution as a result of differences in scale between local interactions and global 
effects. In his view, "evolutionary progress appears continuous on the level of the individual, but discontinuous on the level of a whole population" [29, p. 155]. Moreover, he argues, these effects are purely statistical. As Damerow explains,

I pointed out that discontinuities in evolution appear primarily as statistical effects of small individual changes, but that this is not their real nature. They rather represent qualitative changes in a population or, more generally, in an indefinite set of individual events [29, pp. 158-59].

The theory of punctuated equilibrium formulated by two renowned paleontologists Niles Eldredge and Stephen Gould has been by far the most successful attempt to confront discontinuities in that it has attracted the most attention. However, it has also proved to be one of the biggest sources of controversy in the study of evolution. Punctuated equilibrium has turned the problem of discontinuity into a major issue in evolutionary biology [37].

Eldredge and Gould also trace global speciation-the emergence of new species-to incremental continuous changes that occur on the local level. They argue that favorable variations can become stabilized in relatively small and isolated populationswhat they call "reproductive isolation"--where they would not be overwhelmed by interbreeding. Once favorable variations are secure, natural selection will do its work and select them for fitness [37].

As has been mentioned, the attempt by Eldredge and Gould to explain the absence of evidence for transitional forms has generated much controversy. The theory they have proposed effectively decouples the micro and macro level of evolution by bringing in accidental and external agents that create reproductive isolation [38, p. 648]. This explanation has given rise to an uncomfortable suggestion that "large-scale evolution is guided not by natural selection, but by a separate, though analogous, process" [38, p. 646]. Such claim could not fail to produce fierce and vitriolic debates that abound in the history of the theory of punctuated equilibrium [39, p. 24].

Due to the failure of theorists to resolve conclusively the continuity-discontinuity issue, practitioners in evolutionary biology have had little choice but to resort to ad hoc pragmatic explanations that heavily rely on contingency [40]. Like randomness that characterizes much of the Darwinian model [17], chance and contingency also put such explanations on a shaky foundation. Just as randomness, chance and contingency also cannot pass the test of rational justification, which makes their assumption an act of arbitrariness. Obviously, explanations based on arbitrary assumptions will always appear to be subjective and, as such, open to objections and criticism.

Moreover, the contingent and accidental causes brought to explain discontinuities in evolution are not even biological in nature. More often than not, they are agents external to biology altogether. It could be, for example, a comet, a massive volcanic eruption, or some other such event. Using contingency and, moreover, contingency that is not related to biological processes, puts the Darwinian model in double jeopardy. One can accept contingency in one or two cases but when we deal with five or more major discontinuous events, as is the case with mass extinctions, one finds a contingency explanation hard to swallow, especially if the causes come from outside biology.

The Controversy Over Competition/Egotism vs. Cooperation/Altruism

As has been indicated earlier, the term "natural selection" is a misnomer. When used by itself, it has no meaning since in the Darwinian model there are no selectionists and no actual selection is taking place. This term derives its meaning from another concept widely used by Darwin and his followers "the struggle for survival." As Darwin explains in his On the Origin of Species by Means of Natural Selection, or the Preservation of Favoured Races in the Struggle for Life, organisms constantly struggle--either against each other or against elements-to survive under conditions of limited resources. In the course of this struggle some will endure and others will become extinct. This struggle is the process of natural selection.

As Darwin was well aware, the struggle for survival may take different forms. It occurs either between different species (interspecific) or within the same species (intraspecific); it may involve competition or cooperation. Although Darwin recognizes the role that cooperation may play in evolution, the primary 
focus in his book is on competition to which devotes much more attention than to cooperation.

The new evolutionary synthesis of the 1930s and 1940s has inherited the focus on competition from Darwin's original formulation. The addition of genetics was particularly important in this regard. The proverbial "selfish" gene provided support that further bolstered the focus on competition [41]. As a result, the modern Darwinian model of evolution has firmly embraced the notion that competition is indeed the principal engine of evolution $[42,43,44]$.

This view dominated the study of evolution until the mid-1970s. The publication of Sociobiology: The New Synthesis by E. O. Wilson was a decisive departure from the traditional focus on competition. In this book and in his subsequent contributions Wilson formulated a new perspective that has challenged the view that nature was essentially "egotistic" and competition was the main engine of evolution $[45,46,47,48,49]$.

The new perspective has quickly gained momentum. Its proponents have published numerous theoretical and empirical studies where they develop their main argument that "altruism," not "egotism," is the dominant characteristic of nature, and that cooperation, not competition, drives evolution [47, 46]. Some champions of the new perspective are even calling for a complete revision or even abandonment of the Darwinian model. The following statement by James MacAllister at the Royal Society evolution meeting in London has captured headlines:

Darwinian competition causes not the evolution of species but the destruction of species. It is collaboration in its various forms that causes biological evolution. Hence I'm surprised by calls for extending the neo-Darwinian Evolutionary Synthesis. You can't extend something that is broken. Surely what is needed now, after 65 years, is using the empirical evidence to develop a new paradigm for biological evolution [16].

John Stewart another proponent of the cooperative perspective has widely publicized a view that challenges the Darwinian model on two counts. Not only does he argue that cooperation plays a more important role in evolution than competition, but he also insists that evolution has a direction that is defined by cooperative symbiotic interactions among organisms [50].

Despite decades of fierce and often vitriolic debates, the controversy still continues. Many who study evolution try to reconcile the two sides [51, 52], but despite their efforts peace remains elusive. The community of evolutionary biologists continues to be deeply divided.

In many ways, the eruption of this controversy is due to inconsistency of the Darwinian model itself. This model emphasizes adaptation as the principal mode of interaction between the organism and the environment that plays a crucial role in evolution. By adapting to the environment an organism increases its fitness, thus evolving and improving its chances for survival. Since the orientation of adaptation is always towards environment and its objects, rather than toward the organism itself, this mode of interaction is not, in this sense, "egotistic" and could well be described as "altruistic."

At the same time, the Darwinian model recognizes the important role that reproduction-for example, reproduction of genetic variations--plays in evolution. It maintains that without reproduction of variations, there can be no evolution. The focus of reproduction is on whatever it is that it reproduces, not on the environment. For example, genes use available resources to reproduce themselves. In other words, reproduction involves the inclusion, or assimilation, of objects/resources available in the environment into the internal functional operations of the organism. The object in this case is the internal function, not the environment. Since the orientation in assimilation is toward the internal function, rather than the environment, it may well be described, in this sense, as "egotistic." Dawkins has a good reason to describe genes as selfish [41].

Thus, according to the Darwinian model, both the assimilative ("egotistic") and the adaptive ("altruistic") mode of interaction play an important role in the life and evolution of organisms. However, while recognizing the importance of both assimilation and adaptation, the Darwinian model does not explain the relationship between the two. If assimilation is important on the genetic micro level, how does adaptation emerge on more advanced levels of the organism's 
development? Does assimilation lead to adaptation? How come that the initial "selfishness" of the gene has adaptive "altruistic" consequences?

The Darwinian model does not offer any answer to these questions. In fact, it does not really discuss the relationship between assimilation and adaptation and treats them as largely separate modes that are opposed to each other. The proponents of the Darwinian model have no choice by to emphasize one over the other, which is what leads to confusion and controversy. The only way to resolve this controversy is to understand the relationship between assimilation and adaptation. The Darwinian model does not provide such understanding. Moreover, it does not even offer much of a discussion of this issue.

\section{The Problem of Consciousness}

There is hardly a problem more central to the Darwinian project that the problem of mind and consciousness. After all, the intention that motivates this project is to prove that the evolution of nature is unguided and unplanned. Consequently, it must show that there is no intelligence behind the evolution and all its wonderful creations, including humans, are products of spontaneous forces of nature that in principle can have no idea about the outcomes of their actions. There is nothing that can prove this point more convincingly than by demonstrating that spontaneous and blind forces of evolution can produce intelligence that is capable of reflecting on itself and on the forces that produced it.

Yet, as important as this problem is, the Darwinian model has so far proven to be incapable of resolving it. Years of research by evolutionary biologists and paleontologists aided by studies of mind and consciousness in a variety of disciplines that include psychology, neuroscience, neuroquantology, computer science, philosophy of mind, artificial intelligence and others have not produced any solution. Despite numerous studies, an extensive and constantly growing body of literature, and over a dozen theoretical perspectives on the way mind and consciousness work [53], we are no closer today to getting answers than we were at the beginning of the Darwinian project $[54,55]$.

Daniel Dennet's book is perhaps the most successful current application of the Darwinian model to mind, thinking, and consciousness [56]. However, even this relatively successful venture raises more questions that it provides answers. For one thing, Dennet's application of the Darwinian model has required the postulation of memes-mental equivalents of genes whose existence is yet to be proven and whose emergence, if we are to take Dennet's word for it, may very well have been a happy accident. As Dennet's story goes, after their emergence memes literally invaded human brains and turned them into human minds. "Our thinking," Dennet concludes, "is enabled by the installation of a virtual machine made of virtual machines made by virtual machines" [56, p. 341]. This formulation reminds one of Winston Churchill's famous adage about "a riddle, wrapped in a mystery, inside an enigma" to which one is tempted to add "enclosed in a puzzle" to compound the mystery.

So, the failure to explain the emergence of mind and the rise of consciousness does not appear to be due to a lack of trying. There seems to be a conceptual obstacle to resolving this problem. Pierre Blanquet, among others, views it as a challenge not just for science but also, and primarily, for philosophy [57].

There are even some considerations that suggest that the Darwinian model in principle may very well be incapable of solving the problem of the origin of mind and consciousness, and consequently, explain the rise of humanity. According to this model, biological evolution rewards biological advantages. It sees fitness-biological fitness in the case of biological organisms-as the most important criterion in determining which organism gets rewarded and which does not. Mind and consciousness are decidedly not biological properties. Consequently, they offer no biological advantages. This is not to say that they do not offer any advantages; they most certainly do and these advantages may have implications for biological success. However, these advantages are not strictly speaking biological. Therefore, according to the Darwinian model, the evolutionary success of human species should not depend on mind and consciousness; and, in fact, such dependency may not actually exist, if one is to take seriously the current sustainability crisis that we experience. 
Yet the Darwinian model insists that since human species dominate nature, evolution must favor mind and consciousness. What immediate biological advantages do they offer? The advantages of having the capacity to perform symbolic operations and reflect on them are not immediately clear. A human infant has no biological advantages over a baby chimp. Human babies do not even have cognitive advantages over a chimp in the first year of their life [58, 59]. In the framework of the Darwinian project, the conclusion that biological evolution rewards non-biological traits cannot be unacceptable. If biological evolution rewards mind and consciousness, nature must have some means and ways to appreciate the significance of these non-biological traits-an anathema to the Darwinian project.

The emergence of human species and the rise of consciousness represent a discontinuity that has irrevocably changed the natural balance in human favor. In order to resolve the problem of the origin of mind and consciousness, the Darwinian model must explain discontinuity. As has been shown earlier, the only Darwinian strategy for dealing with discontinuity involves multiplying hypotheses and bringing in factors from outside biology. Although, as has also been explained, this strategy is not unproblematic, even this questionable strategy is unusable in the case of consciousness. Using this strategy in resolving the problem of consciousness will inevitably require positing the existence of at least some predisposition toward consciousness in nature, which contradict the main thrust of the Darwinian project.

Therefore, the strategy of dealing with discontinuity has to change. The new strategy should explain discontinuities, including the emergence of mind and consciousness, as arising from biological processes. As has been shown earlier, evolution theorists relate the problem of discontinuity to the broader problem of the relationship between equilibrium and disequilibrium. The debates provoked by the theory of punctuated equilibrium suggest that the solution of the problem of discontinuity can only emerge from resolving the more fundamental problem of the relationship between equilibrium and disequilibrium, which will require a revision of the entire Darwinian model since it already has an established strategy for dealing with discontinuities. There is no evidence of even a possibility of such revision in contemporary biology and evolutionary studies.

Finally and most importantly, the Darwinian model explains the emergence of order out of chaos. New species that represent a different level of organization emerge out of random mutations or some contingent influences that have little to do with biology. In other words, it posits reality as chaotic. Order, according to the Darwinian model, actually emerges as a result of natural selection. Natural selection eliminates unfavorable traits that are disadvantageous. Consequently, order is what is left when disorder is removed. If order is what is left, then it must exist, at least in some incipient form, prior to the elimination of disorder, which means that order is not created and that it is always there. Such conclusion leads to yet another paradox that the Darwinian model creates.

The unresolved problems and controversies reveal limitations of the Darwinian model. The model requires additional hypotheses and assumptions, some arbitrary, which makes its application bulky and often unwieldy. As a result, the model loses its universal appeal both in biology and in other disciplines. Some even call neo-Darwinism - the current incarnation of the Darwinian model-"the biggest mistake in the history of science" [16].

The declining appeal of the Darwinian model leads to the emergence of other models and descriptions of the process of evolution. In his contribution to New Scientist Mark Buchanan discusses some important alternatives to the Darwinian model of natural selection. He emphasizes, for example, the transformative role of lateral thinking and horizontal gene transfer between organisms in explaining the evolutionary process. Although the Darwinian model remains dominant, the article concludes, other evolutionary models deserve more attention [84].

In today's study of evolution, for example, regulation attracts increasingly more attention. Perhaps this reason explains the growing interest in epigenetics and phenotypes for understanding evolutions. Thanks to epigenetic controls (cellular mechanisms that affect how genes are expressed), even genetically identical 
organisms can display very different traits. Pioneering works by Eva Jablonka, Marion Lamb, and Michael Lachmann offer an alternative to the standard narrative of evolution [60, 61, 62]. Epigenetics may be one important reason "why the popular understanding of evolution might need revising," but there are others $[63,64]$.

Theory of self-organization is another perspective that generates a great deal of interest among biologists who seek to expand the range of theoretical tools that help address unresolved problems. Their particular interest is in understanding the relationship between natural selection and self-organization [81, 82].

The differentiation emerging in the study of evolution creates an impression that there is not one but many very different evolutionary processes. This development undermines the very concept of evolution as a unitary process: evolution can only be evolution if it is a unitary process. This is not to say that it cannot take specific forms in different domains. However, if we are to take evolution seriously, we must conclude that these specific forms should share some essential features characteristic for the process of evolution that connects all levels of organization of reality-from subatomic particles to humans and civilizations. In the absence of such features, different levels of organization appeared to be disconnected, which undermines the very concept of evolution as a universal process.

This is not to argue that the Darwinian model is wrong and its critics are right. This is simply to point out the degree of disagreement and contention that exist in today's study of evolution. Indeed, disagreements can and often are productive but their enduring nature suggests that a rethinking of the Darwinian model may be in order.

The history of scientific knowledge teaches us one important lesson: even if a theory is successful, one can and must question its uniqueness [16]. Does the Darwinian project allow one and only one model or are other models possible? The number of biologists calling for change in how evolution is conceptualized is growing rapidly. The pressure is mounting to include newly discovered phenomena, such as phenotypic plasticity, niche construction, inclusive inheritance and developmental bias [4]. Strong support comes from allied disciplines, particularly developmental biology, but also genomics, epi-genetics, ecology and social science $[11,65,60,61,66]$. Pigliucci is one among many who calls for creating an Extended Evolutionary Synthesis [67].

In view of the problems and controversies that remain unresolved in the Darwinian model, one can and, indeed, must explore possibilities of creating other viable models that will not have the problems and controversies that the current one has failed to resolve. Such exploration of other possibilities does not mean the rejection of the Darwinian project. On the contrary, the motivation, if not the obligation, to explore other possibilities comes from the very imperative to conserve the project by moving it forward.

\section{Conservation, Creation, Evolution}

The conservation anomaly constitutes the most serious problem for the Darwinian model. The law of conservation is widely recognized as universally valid. There is abundant empirical evidence that shows that conservation operates at many different levels of organization of reality. If additional hypotheses can explain, if not entirely resolve, many other controversial issues that arise within the Darwinian model, there are no hypotheses that address the conservation anomaly. In fact, the Darwinian model does not even recognize the fact that it has a problem with conservation. Moreover, there cannot in principle be any hypothesis that would explain this anomaly. There are only two possibilities: either the Darwinian model is right and then we have to revise our view of conservation as universal, in which case, the Darwinian model comes into conflict with many other disciplines and fields of knowledge that recognize the universality of conservation, or the Darwinian model is flawed and requires changes.

Since conservation is at the heart of the principal disagreement between the Darwinian model and the general recognition of universality of conservation, a closer look at conservation and the way it works is in order. It is beyond the scope and intention of this word to discuss the source of conservation. A simple acceptance of a well-known and widely recognized fact of its existence is certainly 
sufficient. After all, the current theory of evolution does not dispute the fact of conservation but only raises doubts as to its universal application. One can safely start with a general observation that all systems, including biological ones, obey the law of conservation and, therefore, all have a natural propensity for conserving themselves. So how do systems conserve themselves? How does conservation work?

All systems have functional operations--that is, they do something. The capacity to do what they do defines systems and is their most important property. They are what they do. Therefore, conservation is about conserving the functional operations of a system.

Functional operations are forms of action; and the only way to conserve action is by acting it out. Therefore, the more functional operations are used, the better they, and the system they make up, are conserved. Evolution favors systems that exercise their functions as much as possible since such systems conserve themselves better.

In order to do what they do, systems require resources. Resources are critical for conservation. Since resources are always finite, systems must be frugal and use their resources efficiently. The more efficiently a system uses resources available to it, the better it is conserved. Evolution favors those systems that use their resources very efficiently.

However, no matter how frugal a system is, no matter how efficiently it uses its resources, these resources are still limited. While frugality helps and is rewarded by nature, it does not solve the fundamental problem of the finitude of resources. The only way to solve this problem is by accessing new resources. Since it is the only way to solve this problem, evolution must favor systems that are capable of gaining access to new resources.

In order to gain access to new resources, a system must expand its range of possibilities-new ways and capacities to act-which requires new properties that are different from those that the system possesses. In other words, expanding the range of possibilities requires the inclusion of differences. The inclusion of differences enriches the system and makes it more powerful. Thus conservation requires changes that make a system more powerful. In order to conserve itself, a system must evolve. Conservation is the engine of evolution. A system that does not evolve cannot conserve itself and begins to disintegrate [68].

All systems have a mechanism that regulates their functional operations. Since this mechanism regulates all functional operations, it has more power-that is, its range of possibilities is wider-than each individual operation or their sum total. Its power represents a multiplication, not a sum total, of all possibilities of all functional operations of the system. In other words, its range of possibilities exceeds all possibilities of all functional operations of the system, which means that the regulatory mechanism is capable of recognizing what the system is not. It has the power of negation. Its level of organization is more powerful than that of any other level of organization in the system and, in this sense, it transcends the system. Due to its power, the mechanism of regulation plays a critical role in systems. It regulates functional operations and their interactions. It also controls all interactions between the system and its environment.

Regulation is a global function. Its primary role is to conserve the entire system, which includes the mechanism of regulation. In other words, regulation also needs to be conserved. If regulation is not conserved, the entire system will start disintegrating. The principle in conserving regulation is the same as conserving any other operation: it has to be active. The more regulation is activated, the better it is conserved. The most proximate source of activation is local functional operations of the system. Thus, conservation of the regulatory mechanism requires multiple connections between this mechanism and local functional operations. Such integration involves both assimilation and adaptation.

Since the global level of organization at which regulation operates is the most powerful level in the entire system, regulation can assimilate local functional operations and include them into its operational schemes. Donald Campbell points to this phenomenon in his discussion of the so-called "downward causality" that involves the influence operations at the local level by the more powerful level that regulates them [83].

The process of adaptation of local operations to the global regulatory level leads to the differentiation of 
regulation. Once local functional operations are included, they have to adapt to the powerful global operations, which enriches them. Such adaptation requires making global operations accessible to local ones, which means that the less powerful operations must "understand" more powerful ones. The translation of operations of greater power into the terms of operations of lesser power involves the emergence of a new frame that has sufficient power to include both the local and the global level as its particular cases. The emergence of this new frame marks the beginning of a new cycle in the evolution of the system.

Using their own functional operations is not the only way systems can conserve themselves. Environment, including other systems, offers a large array of differences that can be used to conserve a system. Since the regulatory mechanism is more powerful than all the local functional operations that constitute a system, it has the capacity to transcend the boundaries of the system. It can sense excitations in the environment of the system, including excitations created by other systems, not just those that originate within the system. The regulatory mechanism can also use these external excitations for its conservation.

Thus, regulation allows establishing connections between the system and its environment, including other systems. The result of such structural coupling-the term used by neurobiologists Humberto Maturana and Francisco Varela [69]—of regulatory mechanisms of different systems is coordination of regulatory operations of different systems and the eventual emergence of a common regulatory mechanism and a new structural whole in which each constituent part becomes a subsystem. Such new integrated functional totality offers more possibilities and, consequently, to a greater array of resources. The common regulatory mechanism activates subsystems more often, which also helps in their conservation.

No matter which path the system takes-internal, external, or a combination of the two-the outcome is the same: the emergence of new and more powerful levels of organization with a more extensive array of possibilities. The wider array of possibilities allows access to new resources and greater stability. As a result, the system is better conserved; and whatever is conserved better is "selected for fitness."

An example from early child development described by famous psychologist and cognitive scientist Jean Piaget in his book The Origin of Intelligence in Children is a good illustration of how systems evolve [70]. For Piaget, the starting point in this development is reflexes that are triggered by nerve signals. Neural functions regulate physiological functions (for example, muscle contraction). Signals from neurons activate physiological functions and thus conserve them. The more frequently this triggering occurs, the more active and, consequently, more stable these physiological functions are going to be. Thus neural networks regulate physiological functions and conserve them. Combined together, neural and physiological functions constitute sensory-motor operations.

Sensory-motor operations, or schemata in Piaget's terminology, are also subject to the law of conservation. They conserve themselves in two ways. First, they become increasingly oriented toward external reality in search of stimulation. This process evolves from casual encounters with stimuli to random groping in search of stimulation, and then to a more directed search for stimuli. The directed search leads to the gradual construction of the object on the level of sensory-motor operations (although not yet on the representational level). In other words, the child begins to simulate the presence of an object that the child has assimilated into sensory-motor operations in previous encounters (for example, simulating hand movements necessary for grasping an object). As more objects are incorporated into sensory-motor schemata, the infant becomes increasingly more orientated toward the external environment.

Sensory-motor operations (for example, tactile, audio, visual, gustatory, and other functions) also conserve themselves through mutual assimilation; that is, by including each other into their assimilative schemata. One example of such mutual assimilation is the activation of the audio function by the visual one, and vice versa. Piaget discusses several such instances. For example, he notes that at a certain age when the infant hears mother's voice, the child begins to turn the head, searching for the familiar image. Mutual assimilation of sensory-motor operations results in the 
emergence of stable connections between them and common regulation. As a result of the emergence of common regulation, each sensory-motor operation receives more stimulation and consequently is better preserved. The common regulatory mechanism offers more possibilities for stimulation and, therefore, is more powerful than the level of each sensory-motor operation or their sum total; these operations become particular cases in this more powerful arrangement. The adaptation of sensory-motor operations to this new totality completes the process. This new and more powerful level of organization gives rise to permanent mental representations that are equivalents of sensory-motor operations on the level of neural organization. The process is completed at the beginning of the second year of life when infants begin to look for objects that are hidden from their direct view. The search for a hidden object indicates that the object is present in the child's mind even when it is not in front of him or her; it indicates that the infant has already constructed a permanent mental image of the object.

The emergence of neural networks that give rise to mental images marks the beginning of a new cycle in child development. While these networks regulate and conserve sensory-motor operations, they also require conservation. Such conservation involves mutual assimilation of networks, creation of a common regulatory level of organization with subsequent assimilation into and adaptation to this new totality. Regulation stabilizes these connections and open the path for the development of symbolic operations, or what we commonly call thinking.

As this section shows, conservation is an essential property of the universe. It is due to the very unique nature of the universe. Conservation is truly universal since it is ubiquitous. The universe would not exist without it. As this section also shows, conservation requires the creation of new and increasingly more powerful levels of organization that provide access to new resources that make conservation possible. Evolution is a result of this process. Thus conservation, creation, and evolution are integrally connected and cannot exist without each other. Conservation fuels both creation and evolution and is, in turn, impossible without them.

\section{The New Model of Evolution}

\section{Comparing the Two Models}

The recognition of conservation as the principal engine of evolution gives rise to a new model of the evolutionary process. This model shares some similarities with the Darwinian model but also has some significant differences. Like the Darwinian model, the new model also sees evolution as unplanned, undirected, and non-teleological process; and this model, just like the Darwinian one does not involve any consciousness, natural or supernatural, that may be involved in guiding it. Although one could regard conservation as the goal that is intrinsic to the evolutionary process, this goal certainly does not amount to a telos - a final goal to be attained in a distant future; there are no final causes involved in the new model. Conservation is not a final cause; it is a very proximate cause that is present at every stage of the evolutionary process. Thus the new model is absolutely compatible with the Darwinian project.

The Darwinian model maintains that there is no direction in the evolution. Yet, we do see evolutionary advances in the complexity of behavior and neural organization that supports this increasingly complex of behavior. Although the new model recognizes the existence of direction toward the emergence of increasingly more powerful levels of organization, but it also recognizes that the direction of evolution is not due to some preconceived or pre-ordained plan. It emerges from the need to conserve the existing level of organization by creating a more powerful one-a proximate, rather than a final cause.

In contrast to the Darwinian model in which conservation plays a subsidiary role, the new model emphasizes the equal and interdependent relationship between conservation and evolution. As many other fields of knowledge and disciplines do, the new model views conservation as truly universal. It does not consider any exceptions to conservation possible. The recognition of the importance of conservation and the recovery of its universal status is a very important difference between the new model and its Darwinian predecessor. There is no conservation anomaly in the new model

The principal focus of the Darwinian model is on 
organisms, species, populations, etc.; in other words, it focuses on specific forms. By contrast, the new model focuses on levels of organization. A definition may at this point be in order. What are levels of organization? Biology recognizes their existence and even uses the term. References to levels of organization are prominent in the life sciences and their philosophical study; they appear in introductory textbooks, as well as in cutting-edge research. Donald Campbell, for example, emphasizes that levels of organization are much more useful in discussion of biological evolution that arbitrary schemes of classification [83].

Yet, in spite of the ubiquity of the notion, levels of organization have received little explicit attention in biology or its philosophy. Usually they appear in the background as an implicit conceptual framework that is associated with vague intuitions.

Since levels of organization have received little attention, there is no widely accepted definition of what a level of organization is, although many can and do identify specific levels of organization, such as subatomic and atomic, molecular, cellular, tissue, organ, organismal, group, population, community, ecosystem, landscape, biosphere, etc. In the absence of a general and widely applicable definition, a working definition may be helpful. A level of organization is a network of structurally connected components that has its own distinct level of combinatorial power-that is, it offers a certain distinct set of possibilities that represents its unique power. The characteristic feature of each level of organization is the array of possibilities that it offers. For example, the nervous system in an organism represents a level of organization that has sufficient combinatorial power to regulating biological functions of the organism. Human brain represents another level of organization that is capable of regulating neural functions. It is the most powerful level of organization that exists in nature. It derives its power from the capacity to create an infinite number of new and increasingly more powerful levels of organization that are capable of sustaining an equally infinite array of behavioral modes.

Viewed from the perspective that focuses on specific forms-one that is used by the Darwinian model --evolution appears to be an erratic, unsteady, and inconsistent process punctuated by sudden leaps and reversals that are hard to explain. By contrast, when viewed from the perspective that focuses on levels of organization, evolution emerges as a steady and consistent process that produces increasingly more powerful levels of organization. In accordance with this perspective, the evolution shows no exceptions to conservation. No level of organization ever becomes extinct; all levels are conserved. There are no reversals and no instances of non-conservation. When one views the evolution from the perspective of forms, one can observe that about 95 percent of all living species have become extinct. Viewed from the perspective of levels of organization, one can see that levels of organization that once dominated the life world are no longer dominant; yet some species that represent levels of organization that lost their dominant position have survived to this day. These levels of organization have not disappeared; they have just lost their dominant position to other more powerful levels of organization. Moreover, new and more powerful levels of organization include the essential features of the levels they displaced from the dominant position and, thus, also conserve them. Humans now dominate our planet. Some of the species that had dominated our planet before the emergence of human race disappeared but many continue to exist. However, the level of organization that sustains the human race retains all the essential features of all the levels of organization that have preceded it.

Also, according to the perspective that focuses on levels of organization, each stage of the evolution has its own object of conservation. This object is always the most powerful global level of organization that supports the mechanism of regulation. There is no need to conserve other levels since the global level already conserves them. Nature is frugal and does not like conspicuous consumption. It conserves only what needs to be conserved. What has already been conserved does not need any additional conservation.

Finally, when viewed from the perspective of levels of organization, one can see that the process of evolution represents a steady increase in power of new emerging levels of organization all the way to human brain that represents the most powerful level of organization in nature. Even though many specific organisms have become extinct, the evolution of neural 
networks and modes of behavior they are capable of sustaining shows steady growth-no reversals and no extinctions. Pierre Teilhard de Chardin, a famous French philosopher and paleontologist, was one of the first who pointed to this steady increase in his famous book The Phenomenon of Man [71]. Today the growth of the power of the neural system in the course of the evolution is a well-documented fact [72].

The focus on levels of organization has two main consequences. First of all, since the object of conservation is the level of organization and the level of organization is always conserved, there is no need to trace evolutionary changes to specific organisms and no need to construct elaborate phylogenetic trees that postulate hypothetical progenitors [14]. Searching for common ancestors is a formidable enterprise that produces mixed results since empirical evidence for such progenitors is often lacking and may even be unattainable. Also, the focus on specific forms privileges differentiation over integration. The available evidence shows that both differentiation and integration play an equally important role in evolution and run parallel to each other. We see as much evidence for differentiation as we see for integration. The evidence we have about evolutionary changes does not support interpretations that privilege differentiation-or, for that matter, integration. A good example comes from linguistics. The Indo-European theory that has been successful in showing relationships among different languages in the Indo-European group has totally failed when applied to ethnic processes. For example, when archeologist and ethnologists tried to identify an ethnic group that spoke the hypothetical proto-Slavic language they failed to determine even the area where this hypothetical group could have been located. The most likely location had no evidence of any population that had ever lived in that marshy area and no artifacts representing its culture [80]. Evolution is ultimately not about differentiation or integration, but rather about advances in power of organization from one kind of complexity to complexity of another kind. The result of the evolution is cascading levels of organization nested matryoshka-style in each other.

The focus on the global level of organization makes the new model applicable in fields other than biology where evolutionary processes are taking place without violating their autonomy. The Darwinian model poses a difficult choice: either one has to reduce non-biological evolution to biological processes, as the Darwinian model often requires (for example, reducing evolution of psychology, behavior, society or culture to genetics), or one has to create a totally different model of evolution that fits a particular field (social evolution). In one case, the Darwinian model becomes excessively reductive and violates the autonomy of fields outside biology. Another route leads to the proliferation of dramatically different evolutionary models. Such proliferation goes against the very conception of evolution as a unitary process. If we are to take evolution seriously, we must conclude that despite differences of the specific areas of instantiation, all these instances of evolution must have common features since evolution makes sense only as a unitary process. The model that focuses on levels of organization is more universal since its application does not require reduction to biology and, therefore, does not violate the autonomy of specific fields where the model is applied.

\section{Conservation-the Engine of Evolution}

The recognition of conservation as the main engine of evolution makes the new model much simpler than the Darwinian one. Conservation replaces the bulky and problematic evolutionary mechanism used in the Darwinian model that involves three components-variability, reproduction, and natural selection.

As has already been pointed out, variability is not an essential condition for evolution. Random variations require additional assumptions about the nature of reality that cannot stand the test of rational justification. Therefore, one has to recognize its subjective and arbitrary nature. Such recognition makes the interpretations based on this assumption vulnerable.

In addition, the emphasis on random variations has generated the controversy with the advocates of Intelligent Design who argue that evolution based on random variations is statistically improbable, if not, indeed, impossible $[86,87,88)$. They often invoke an assertion made by British astronomer Fred Hoyle that the random emergence of a cell is as likely as a Boeing 747 being created by a tornado sweeping through a junkyard. 
The proponents of the Darwinian model have responded to this challenge. In their view, "[p]robability and statistics are well-developed disciplines with wide applicability to many branches of science, and it is not surprising that elaborate probabilistic arguments against evolution have been attempted" [88, p. 45]. Responding to contentions by Dembski and Behe [86, 87, 88], Peter Olofsson, for example, demonstrates in his analysis that their arguments for design based on estimated mutation probabilities "must be purely speculative." He concludes that while such arguments may appear to be convincing, "[c]areful evaluation of these arguments reveals their inadequacies" [89, p. 45].

The proponents of the Darwinian model concede the problematic nature of chance but they further bolster their claim by arguing, as John Rennier does, that evolution does not depend on chance to create organisms, proteins or other entities. Quite the opposite: natural selection, the principal known mechanism of evolution, harnesses nonrandom change by preserving "desirable" (adaptive) features and eliminating "undesirable" (non-adaptive) ones. As long as the forces of selection stay constant, natural selection can push evolution in one direction and produce sophisticated structures in surprisingly short times [90].

In support of his argument Rennier cites the example of complex effects that can be produced by mutations that arise in homeobox (Hox) family of development-regulating genes.

The problem with Rennier's response and similar responses is that they rely on the positive effect of natural selection. The capacity of natural selection to "harness nonrandom change" implies the existence of some notion of positive or desirable change, which contradicts the very thrust of the Darwinian project that wants to make the case for the evolution as an undirected, unplanned, and non-teleological process. The example of the Hox family genes above also raises questions. Since these genes are involved in regulation, they must operate on a more powerful level of organization, one wonders how this level has emerged and whether its emergence was due to random mutations.

The endless debates between the proponents of the Darwinian model and the supporters of creationism and Intelligent Design appear to be utterly futile, as both sides have dug in their heels and refuse to budge. Neither side seems to be capable of claiming a victory. The fruitlessness of these debates makes one wonder why evolutionists would not try a different tack-after all, science is a creative enterprise that offers many possibilities. Why do they persist in approach based on the assumption that is hard to justify and that opponents of the evolutionary approach use against them? Why not try a different approach?

Perhaps the most obvious answer to these questions is that there is no different approach. The proponents of the Darwinian model cannot think of any other source of disequilibrium except randomness and chance to propel the evolution. The assumption of randomness also saves them from the conundrum of infinite regress, as every cause is also an effect that requires explanation. Random variations do not require any explanation; they just are. But perhaps the most important reason is the fact that the assumption of randomness and chance--that, as has been shown, is unjustifiable and highly problematic-is the premise that supports the Darwinian interpretation of the evolution as an unguided, unplanned, and non-teleological process. Unfortunately, this foundation on which the Darwinian model rests is rather weak. As has been indicated earlier, it is unjustifiable. It also provides fuel to the critics who raise questions about the statistical improbability, if not impossibility, of evolution based on chance and randomness. Finally, sustaining the Darwinian model requires many additional hypotheses that make it very bulky and highly complex, which creates a challenge when the model is used in interpretations.

The new model proposed in this study is much simpler. In accordance with this model, conservation that is ubiquitous in nature is all that is needed for evolution to take place. The application of the new model does not require, for example, any additional and problematic assumptions about the putative random nature of reality that cannot in principle pass the test of rational justification and, for this reason, must be recognized as arbitrary and subjective, which makes the interpretations based on this assumption vulnerable to criticism. 
The demotion of variability as an essential condition for evolution also eliminates the contradiction between this requirement and the tendency to trace evolution to common ancestry, that is, to a source in which variability is limited or even non-existent. This is not to say that variability is insignificant or unimportant. Variability provides differences, and inclusion of differences is certainly a factor in creating new and more powerful levels of organization, which advances evolution. In this sense, variability is important. This is to say, however, that variability is only a valuable complementary factor that facilitates evolution, rather than a causal one.

Replication is another factor that may not necessarily and always be conducive to evolution. The Darwinian model recognizes that evolution is about survival and fitness. Survival requires resources. Successful fitness leads to successful replication. But replication increases the number of organisms that use the same resources, which increases the depletion of these resources. The depletion of resources is not conducive to survival and, consequently, to evolution. Darwin clearly points to this possibility, echoing a Malthusian argument, in his On the Origin of Species when he writes: "Hence, as more individuals are produced than can possibly survive, there must in every case be a struggle for existence, either one individual with another of the same species, or with the individuals of distinct species, or with the physical conditions of life" [1, p. 63]. Both variability and reproduction complement evolution, but this fact must not overshadow or replace the important role of conservation and the process of creating new and more powerful levels of organization that are both central to evolution. Outside conservation and the process of creation, neither variability nor reproduction can make evolution possible.

As has been mentioned, natural selection is really a misnomer $[73,74]$. Selection involves an act of selecting. It is worth reminding that the practice of artificial selection influenced Darwin in formulating his theory. However, there is nothing in the process of natural selection-and Darwin is very clear on this point-similar to an act of selection for advantageous features that is involved in the practice of artificial selection. In the Darwinian model there is only the struggle among organisms for survival under conditions of limited resources. There is no selectionist involved. Therefore, natural selection is merely a phrase, a convenient expression that Darwin used to explain the struggle for survival. It is merely an outcome of the competition for limited resources that is not a necessary condition without which evolution cannot take place.

Thus, conservation is the single most important factor that makes evolution possible. Indeed, conservation requires evolution and cannot exist without it. The role of other factors discussed in the Darwinian model is complementary; it is in no way equivalent to the powerful role that conservation plays in evolution.

\section{Untangling the Discontinuity Problem}

As has been shown earlier, the current approaches toward resolving the problem of discontinuity within the Darwinian model are in many ways very different. Damerow, for example, sees discontinuities as purely statistical effects on the macro level of the continuous changes-that is, changes in which one can trace causal effects to some antecedent factors-on the micro level [29, pp. 155-60]. By contrast, Eldredge and Gould invoke reproductive isolation as a way of mediating changes that occur on the micro and macro level [37]. However, despite their differences they share common features. For one thing, they view continuity and discontinuity in terms of equilibrium and disequilibrium. They also see that there is some connection, even if mediated, between continuity/equilibrium on the micro level and discontinuity disequilibrium on the macro level.

Thus, efforts to explain discontinuities within the Darwinian model point that the solution of the problem lies in the relationship between equilibrium and disequilibrium. However, since the Darwinian model does not discuss this relationship, it can only relate equilibrium and disequilibrium by bringing in factors that do not emerge directly from the model of the evolutionary process but have to be brought in from outside, either in the form of additional assumptions, such as chance and contingency, or in the form of facts that are not biological in origin.

In contrast to the view that sees continuity and discontinuity as separate and diametrically opposed to each other, there are several contemporary theoretical 
perspectives-such as systems theory, theory of emergence, complexity theory, theory of self-organization, and others-that view both equilibrium and disequilibrium as two essential and closely interrelated aspects of reality that are complementary, rather than opposed to each other. They believe that since both equilibrium and disequilibrium coexist within the same system, there is a direct link between the two. In their view, reality is neither chaotic nor orderly but always exists -in a felicitous description of Stuart Kauffman-"at the edge of chaos" [75, 76, p. 131]. The new perspectives believe that since equilibrium and disequilibrium coexist within the same system, they must be related to each other, even if the explanation of this relationship still remains elusive. Consequently, they seek the solution of the problem of discontinuity in explaining this relationship [77].

As the discussion of the relationship between conservation, creation, and evolution points out, the balance between equilibration and the production of disequilibrium is essential for conservation. It makes possible the emergence of new and increasingly more powerful levels of organization. The emergence of such levels represents an evolutionary process in which incremental local interactions result in the emergence of new and increasingly more powerful macro levels of organization that cannot be reduced to the levels of organization from which they have emerged due to power differential.

According to the description provided in this study, conservation leads to the creation of new and increasingly more powerful levels of organization. The process of creation involves both equilibration and the production of disequilibrium. Although equilibration is a form of continuity, it produces, as has been explained, disequilibrium that is a source of discontinuity. Without understanding the close relationship between conservation, creation, and evolution, we cannot grasp the fundamental connection between equilibration and the production of disequilibrium, between equilibrium and disequilibrium. As a result, equilibration and the production of disequilibrium will appear as two disconnected modes opposed to each other. Only in the context of conservation and the process of creation that it requires, we can grasp this connection-the fact that reality always balances on the cusp of equilibration and the production of disequilibrium, or equilibrium and disequilibrium.

The discussion of the relationship between equilibration and the production of disequilibrium makes obvious the role of the balance between the two. Maintaining this balance does not require mediation. It is a product of direct and complementary relationship between equilibration and the production of disequilibrium. As equilibrium grows as a result of equilibration, so does disequilibrium as a result of the emergence of new and more powerful levels of organization that regulate interactions that have produced them. Without understanding the integral relationship between equilibration and the production of disequilibrium, the causal interaction between the two cannot be reconstructed and the effect will appear as a discontinuity.

The insistence that the solution of the problem of discontinuity lies in the direct relationship between equilibrium/equilibration and the production of disequilibrium does not imply that contingency and chance do not have any role in evolution; they most certainly do. However, evolution has too many instances of discontinuity to explain all or even a significant number of them by resorting to contingency and chance-an assumption that does not pass the test of rational justification. If we excessively rely on such assumptions, we run the risk of allowing theory to control us, rather than make sure that we control theory.

This discussion lays out only very general contours of the solution of the problem of discontinuity. No doubt, further theoretical elaboration is needed as well as the empirical evidence that will support it. However, by emphasizing the direct relationship between equilibration and the production of disequilibrium and thus removing this important theoretical stumbling block, the approach presented in this work opens the path toward a conclusive solution of this problem.

Resolving the Controversy Over Competition/Egotism vs. Cooperation/Altruism

The earlier discussion of the issue of competition/egotism vs. cooperation/altruism has shown that this controversy has roots in the two modes that 
the organism uses in its interactions with the environment: adaptation and assimilation. Assimilation has an inward orientation; its object is the organism and its functional operations. Assimilation conserves these operations by including external objects into functional operations of the organism. In this sense, one can certainly describe assimilation as "egotistic." By contrast, the orientation of adaptation is outward toward external objects and the environment, and away from organism and its functional operations. In this sense, adaptation is essentially an "altruistic" mode that conserves the object.

As a mode of interaction with the environment, assimilation precedes adaptation. It is a result of the activation of functional operations of the organism by internal neural signals. For example, internal neural signals trigger the movements of the mouth of a newborn even before this newborn begins to actively interact with the environment. There is no initial purpose to these movements other than exercising, thus conserving, this sensory-motor operation. In another example, the child will grasp whatever touches the palm and activates neural receptors. Only later the child adapts this primary sensory-motor operation to other purposes. Assimilation is the primary mode of conservation: no assimilation, no conservation.

Conservation of assimilative operations creates new levels of organization. Since these new levels of organization are more powerful than that of initial assimilative operations that have created them, these operations have to adapt to these new levels. This adaptation conserves new levels of organization. If they are not conserved, the system will disintegrate. Thus organism "learns" adaptation, which leads to adaptive behavior.

Assimilation precedes adaptation but this fact does not make it any more important than the latter. Both are intimately related--after all, it is assimilation that gives rise to adaptation. Even though their roles are different, they are equally important for evolution. Assimilation creates new levels of organization; adaptation conserves them. Since both modes are equally important, they should be in balance. Such balance is an essential condition for conservation and, consequently, for evolution.
The Darwinianmodel recognizes the "selfishness" of genes as essential for variability and the evolutionary process that this model describes. As a result, it has to recognize the competition among "selfish" genes as central to the evolutionary process. However, the Darwinian model also emphasizes adaptation as a mode of interactions that plays an important role in evolution. As has been indicated earlier, adaptation is essentially "altruistic" in that it treats reality as autonomous from the organism. Although cooperation does not necessarily require altruism, the association between the two is strong.

The Darwinian model of evolution does not see conservation as central to evolution. Consequently, it does not consider or discuss the process of creation. As a result, assimilation and adaptation appear as two separate modes opposed to each other; and the application of the Darwinian model requires making a choice where no choice should be made since both competition/assimilation and cooperation/adaptation are but two equal aspects of the same process and are equally important. The Darwinian model can only see assimilation and adaptation-and consequently, competition and cooperation-as two separate modes that are opposed to each other.

The new model presented in this essay sees conservation as central to evolution. Conservation requires the equilibration of functional operations. Such equilibration establishes stable connections among various functions of organism. In the course of equilibration functions include each other into their respective operational schemes, which is a form of assimilation. Their equilibration leads to the emergence of a new and more powerful level of organization. Conserving the new level requires its integration with the level of organization of functional operations from which the new level has emerged. Such integration involves adaptation of functional operations to the new and more powerful level of organization. Thus, the conservation of "egotistic" functional operations leads to the emergence of "altruistic" adaptation. Conservation that starts with assimilation leads to the emergence of adaptation. Thus organism "learns" adaptation and adaptive forms of behavior. Subsequently, adaptive forms of behavior lead to the emergence of the capacity to recognize differences that eventually evolves into 
awareness of autonomy and altruism that are essentially grounded in the initial egotism and egocentrism.

The new model views assimilation and adaptation as two essential aspects of the same process of creation that complement each other. Assimilation creates new levels and adaptation conserves them. No new level of organization can emerge without conserving preceding levels. Both aspects are equally important and complement each other in the process of creation. Thus, the new model shows that there is no controversy between competition/egotism vs. cooperation/altruism. The controversy emerges only if the process of creation is not in the frame of vision. Only when we do not consider this process competition/egotism and cooperation/altruism emerge as two distinct modes in opposition to each other.

\section{The New Model and the Problem of Mind and Consciousness}

Despite all the mysteries and paradoxes related to human mind, conservation is as much a part of what the mind is and does as it is of any other level of organization; and, as has been argued earlier, conservation inevitably leads to creating new and increasingly more powerful levels of organization (in this case, organization of neurons and neural networks). There is little difference in this capacity to create new levels of organization between human mind and the rest of nature; the only difference-and it is a major one-is that human mind can create an infinite number of such levels of organization.

If we recognize that capacity for reflection is the most important property of human consciousness-and we do [78]. then we have to acknowledge that this capacity is the property that characterizes any form of regulation that exists in nature. The only difference between consciousness and other forms of regulation is the capacity of infinite reflection-that is, reflection upon reflection, or self-reflection, in the case of consciousness. No doubt this is an important distinction but not one that emerges from nowhere; its basic functional features emerge from numerous forms of regulation that have existed prior to the rise of consciousness.

As has been indicated earlier, the problem of consciousness presents a special challenge to the
Darwinian model. Tracing evolutionary advances to genetic mutations has some uncomfortable implications in the case of consciousness. Genetic mutations are biological phenomena that offer advantages or disadvantages that are biological in nature. Consciousness is not a biological property and therefore does not offer advantages that are biological. The reason for selecting a property that offers no biological advantage must be non-biological. Where does this reason come from? Why does a biological evolution favor such selection? The Darwinian model does not give a clear answer to these questions and has so far failed to solve the problem of consciousness.

Moreover, there is an indication that the Darwinian model simply cannot solve this problem. The emergence of consciousness has changed the balance of nature in favor of humanity. As such, this emergence represents a dramatic discontinuity in the evolution of life world. The Darwinian explanation of discontinuities does not emerge from the evolutionary process itself; it requires making an arbitrary assumption and provide reasons of non-biological nature. This approach may be uncomfortable in the case of biological discontinuities, but it is completely unusable in the case of consciousness. The Darwinian model cannot refer to any reason in or outside biology that could even potentially give rise to consciousness, other than some wild and totally unwarranted suppositions and speculations.

The new model provides an approach that may help to understand and explain the emergence of mind and consciousness. According to this model, evolution is about creating new and increasingly more powerful levels of organization of reality. Conserving each level requires creating a new and more powerful one. Evolution, whether biological or not, always involves conservation.

In accordance with the new model, the object of conservation is the level of organization, not traits, organisms, species, or populations. These may emerge and prosper, and then decline and become extinct. The level of organization is always conserved and is never extinct. Its conservation requires the creation of a new and more powerful level of organization that, in turn, also has to be conserved, and so ad infinitum. There is no limit to evolution. 
Mind and consciousness represent the most powerful level of organization of reality. This level of organization has the capacity to create an infinite number of new and increasingly more powerful levels of organization. Consciousness operates on the symbolic level, which means that it uses symbols coded in neural connections and networks. The levels of symbolic organization created by consciousness also have to be conserved. As in any other case, conservation of symbolic levels of organization also involves the creation of new and more powerful levels. The only difference with other cases is that there is no limit because there is always a possibility--nay, necessity--to create another level of organization. But this is not all. There are billions of human beings that are capable of creating infinite number of new levels of organization. The combined capacity of all human minds is awesome. There are no limitations that one can even imagine. If we recognize that evolution is about the creation of new and more powerful level of organization, we begin to understand why evolution must favor the emergence of mind and consciousness.

The awesome power of human mind comes from the capacity for reflection. It offers a possibility of infinite reflection, reflection on reflection, and self-reflection. The capacity for reflection has its roots in conservation and creation. Regulation is essential for conservation. Without regulation, systems cannot conserve themselves.

Regulation involves reflection. In order to regulate a system, its regulatory mechanism should have components that correspond to functional operations of the system it regulates; in other words, there should be one-to-one correspondences between the regulatory level and the level of organization of functional operations. These correspondences do not replicate functional operations because the regulatory level is more powerful; these correspondences are equivalents-analogues--that reflect functional operations, not copy them. Thus reflection and regulation go together.

No system, or organism can survive without regulation. Regulation is widespread throughout life world and, indeed, throughout the universe. We can find it at all levels of organization. Regulation is an integral part of evolution [see 79]. As everything related to evolution, regulation has also evolved. The new forms of regulation that have appeared have inherited the essential features of regulation. Reflection is one of them. The infinite reflective capacity of human consciousness is a result of this evolution.

This brief description certainly does not explain all the aspects and intricacies of human consciousness and mind. This complex subject will take many theoretical and empirical studies to reveal the way our mind and consciousness work. This study did not and could not aspire to achieve such goal. All it has tried to do is to open the path to understanding the connection between consciousness and evolution.

The creation of new and increasingly more powerful levels of organization does point in a certain direction. However, this direction is not a result of some preconceived plan; it is not a product of some consciousness. Rather this direction emerges from the essential condition of the survival of our universe-its conservation; and mind and consciousness are merely its results-albeit the most important

To summarize, the new model of the evolutionary process represents an advance over the Darwinian one:

By emphasizing the role of conservation in the evolutionary process, the new model restores the universal status of conservation.

The emphasis on the role of conservation in the evolutionary process does not invalidate the Darwinian model. Natural selection is a key concept in the Darwinian model. This concept implies fitness between organism and its environment. Fitness is the result of the adaptation of an organism to its environment. Adaptation involves behavior-that is, the way organism acts in its environment. Behavior is a general terms for the array of sensory-motor operations and their combinations that the organism is capable of performing. Sensory-motor operations are functions of the nervous system that regulates them. The array of possibilities that the nervous system offers defines the modes of behavior that the organism is capable of performing that ultimately determines the capacity of the organism to adapt to and create a fit with its environment. This capacity, according to the Darwinian 
model, plays a critical role in the survival of the organism and its evolution.

The new model does not contradict the thesis about natural selection and fitness. On the contrary, it expands and elaborates it further. According to the new model, the nervous system that represents the most powerful level of organization in an organism. It regulates all the physiological functions of the organism. It also regulates the organism's sensory-motor operations-that is, the organism's modes of behavior. Since behavior is critical for adaptation and consequently fitness, it plays a critical role in the capacity of the organism to survive. The diversity of possible modes of behavior, more than any other trait, is what determines the survivability of the organism. Size was the principal survival strategy of dinosaurs. This strategy served them well in that it allowed dinosaurs at one point to dominate the Earth. However, it was not a huge and powerful dinosaur, but a tiny mouse that ultimately prevailed in the struggle for survival-a tiny mouse with its capacity to function in the absence of direct sunlight and feed at night.

The nervous system represents the most powerful level of organization in nature. The emphasis on levels of organization and their power in explaining the evolutionary process does not invalidate the Darwinian model. The Darwinian model remains perfectly valid if we focus on fit between organism and the environment, rather than the source of the fit. The new model expands and further elaborates the Darwinian one; it includes the latter into its broader frame as a particular case that remains valid if the source of adaptation and fit is not in the focus of attention.

The focus on the nervous system as the most powerful level of organization does not exclude anatomical traits. These traits play an important role in interactions between the organism and its environment. There is still much to be known about the relationship between the evolution of anatomical traits and the evolution of the nervous system and the modes of behavior it can support. However, there is no doubt that the nervous system of the organism represents a level of organization that is far more powerful that the level of organization of anatomical traits.
In accordance with the new model, the level of organization that matters most at each stage of the evolution is one that is most powerful because the evolution is about conservation, and it is precisely the most powerful level of organization that needs to be conserved. The conservation of this level advances and defines further evolution.

The new model is parsimonious. In contrast to the Darwinian model, it requires no additional hypotheses and assumptions. Parsimony makes the application of the new model in interpreting evolutionary changes easier and more efficient.

The new model explains the emergence of discontinuities as a result of the equilibration involved in incremental changes. It does not resort to any additional hypotheses regarding the nature of reality or attributes discontinuities to non-biological factors. The focus on levels of organization helps understand that while there are discontinuities and leaps in the evolution, there are no and cannot be any reversals.

Unlike the Darwinian model, the new model of evolution does not violate the autonomy of fields other than biology where evolutionary processes also occur. Since the model emphasizes the important role of the most powerful level of organization at each stage of the evolution, it is inimical to any kind of reductionism of non-biological evolutionary processes to biology. This feature makes the new model more flexible in application to non-biological spheres and, in this sense, more universal.

The new model opens the path toward understanding the origin of human mind and consciousness. It helps understand why the conservation of constructs on the neural level of organization leads to the creation of new and more powerful levels of organization that sustain mental images, the capacity for symbolic operations, and consciousness with its capacity for reflection on reflection, or infinite levels of reflection.

Finally, and most importantly, the new model is perfectly compatible with the Darwinian project. In fact, it enhances and further advances this project.

\section{Conclusion}

Evolution is not limited to biology or, for that matter, to any other field. It is truly 
universal. Everything in the universe is a result of the evolutionary process. This revision of the Darwinian project confirms this fundamental point.

The revision does not involve the abandonment of the Darwinian project. On the contrary, it enhances, advances, and thus conserves the project. It does not destroy the Darwinian model but merely creates a broader frame that includes this model as its particular case-that is, a case that is true under specific conditions or assumptions. Indeed, if one does not see the centrality of conservation as the source of evolution, the Darwinian model will appear to be viable. This recognition raises an important question: Is there a compelling reason for embracing revision or, for that matter, any other revision of any other project? And if there is such reason, what is it?

Our civilization has often confronted such questions in the past. The answers did not come easy and only after a protracted period of struggle and resistance. Generally we have accepted change. Justifications of change may have differed is specific formulations but most of them emphasized some lofty idealistic reason, such as the search for truth or a fulfillment of human destiny. One has to admit that both justifications are rather vague. They originate in some metaphysical belief in human predestination. It tells us that we are different from nature. If change in nature is a result of some material causes, changes that humans pursue do not result from material causes but from some reasons that lie outside nature.

Evolution is about reality and material causes and the version of the evolutionary theory presented in this essay observes this fundamental principle. This version is not a result of some idealistic inspiration. It is a product of the same factors that propel the evolutionary process, regardless of where it is taking place: the universe, nature, society, individual, or knowledge. The universal imperative of conservation-everything must be conserved-requires the creation of new and increasingly more powerful levels of organization that advances the evolution.

The revision of the Darwinian project presented in this essay does not abandon the Darwinian project. Rather, it seeks to affirm the validity of this project. As have already been indicated, it does not call for a destruction of the Darwinian model. On the contrary, it creates a broader frame that conserves it as its particular case, that is, a case that is valid under specific conditions or assumptions.

We usually determine the validity of a theory on the basis of a putative criterion of truth that we often understand as one-to-one correspondence between our mental constructs and reality. The problem with this approach is that our mental constructs represent the most powerful level of organization of reality. Therefore, our mind is always capable of establishing one-to-one correspondences between its constructs and reality. So the real criterion for validating a theory or a model is one one-to-one correspondence; the real criterion is how powerful-that is, how inclusive-our mental constructs are.

Does a model or a theory make a difference? Does it really matter which model or theory we use as long as empirical research proceeds apace? It does. A more comprehensive model offers more possibilities and therefore has greater explanatory power. It helps to identify more possibilities both in terms selection of facts and their interpretation. Finally, and most importantly, it opens the path toward further advances that will conserve the current level of mental constructs and move the evolution of our mental organization forward. We cannot conserve our current mental constructs unless we continue to create new and more powerful levels of organization that will give rise to new mental constructs.

If there is a lesson that we can derive from the Darwinian project, it is this: As part of the evolutionary process, we should always aspire to create new and increasingly more powerful levels of organization that can sustain a richer and more inclusive vision of reality. This lesson also teaches us that evolution involves creation. Creation is a process that is open to human understanding. In contrast to religion, we must not relegate this process to the sphere of the unknowable; on the contrary, we can and we must explain this process in rational terms, rather than accept the notion that it is inaccessible to our understanding. If evolution teaches us anything, it is that our mind, our consciousness, our capacity to perform symbolic operations and use them in creating new and more 
powerful levels of organization are its most powerful creations. This realization is the most significant import of the Darwinian project-one that we should preserve and cherish.

\section{Endnotes}

1. One is reminded of an observation made, among others, by Jerry Fodor, a well-known cognitive scientist, that the survival of the fittest just means survival of those that survive, since the only criterion of fitness is that a creature does, indeed, survive and reproduce.

2. Doyne Farmer, a mathematician, has coined the phrase "the edge of chaos" to describe the transition phenomenon discovered by computer scientist Christopher Langton. Stuart Kauffman, a well-known theoretical biologist, has popularized the term.

\section{References}

1. Darwin, C. (1861). On the Origin of Species. New York: P.F. Collier, 1861.

2. Godfrey-Smith, P. (2009). Darwinian Populations and Natural Selection. New York: Oxford University Press, 2009.

3. Descartes, R. (1993). Meditations on First Philosophy. Translated by Donald A. Cress. 3rd edition. Indianapolis: Hackett Publishing Company, 1993.

4. Laland, K., Wray, G. A., Hoekstra, H. E., et al. (2014) "Does evolutionary theory needs a rethink?" Nature, 514: 161-64.

5. Sydow, M. (2012). From Darwinian Metaphysics towards Understanding the Evolution of Evolutionary Mechanisms. Göttingen: Universitätsverlag Göttingen.

6. Mesoudi, A. (2011). Cultural Evolution: How Darwinian Theory Can Explain Human Culture and Synthesize the Social Sciences. Chicago: University of Chicago Press.

7. Mesoudi, A. (2016). "Cultural Evolution: A Review of Theory, Findings and Controversies." Evolutionary Biology, 43 (4): 481-97.
8. Smaldino, P. (2014). "The Cultural Evolution of Emerging Group Level Traits." Behavioral and Brain Sciences, 37: 243-295.

9. Tanaka J. (2010). "Consilience, Cultural Evolution, and the Humanities." Philosophy and Literature 34 (1): 32-47. https://doi.org/10.1353/phl.0.0084

10. Reid, R. G. B. (2007). Biological Emergences: Evolution by Natural Experiment.Vienna Series in Theoretical Biology. Cambridge: MIT Press.

11. Pigliucci, M., Müller, G. (2010). Evolution: The Extended Synthesis. Cambridge: MIT Press.

12. Nei, M. (2014). "Darwin Never Proved Natural Selection Is the Driving Force of Evolution Because It Isn't." Homolog.us. http://homolog.us/blogs/ ncrna/2014/03/05/mutationism/

13. Buchanan, M. (2010). "Evolution, but Not as We Know It." New Scientist, 205(2744): 34-37.

14. Guidotti, T. (2006). "The Phylogenetic Tree Topples." American Scientist. http:// www.americanscientist.org/issues/pub/2006/3/thephylogenetic-tree-topples

15. Monod, J. (1972). Chance and Necessity: An Essay on the Natural Philosophy of Modern Biology. Translated by Austryn Wainhouse. edition. New York: Vintage Books.

16. MacAllister, J. (2017). "The Royal Society's Evolution Meeting: James MacAllister / Why Neo-Darwinism Was the Biggest Mistake in the History of Science." Cosmic Fingerprints. https:// cosmicfingerprints.com/royal-society-macallister/

17. Plotnitsky, A. (2004). "Evolution and Contingency." Postmodern Culture 14(2). http:// pmc.iath.virginia.edu/issue.104/14.2plotnitsky.html

18. Gould, S. (2002). The Structure of Evolutionary Theory. Cambridge: Harvard University Press.

19. Zurek, W. (1989). "Algorithmic Randomness and Physical Entropy." Physical Review A, 40(8): 4731-51.

20. Atmanspacher, H. and Bishop, R. Eds. (2002). Between Chance and Choice: Interdisciplinary Perspectives on Determinism. Thorverton: Imprint Academic. 
21. Bricmont, J. (n.d.). "Determinism, Chaos, and Quantum Mechanics." http:// www.freeinfosociety.com/pdfs/mathematics/ determinism.pdf.

22. Bricmont, J. (2016). Making Sense of Quantum Mechanics. 1st ed. New York: Springer.

23. Buchanan, M. (2008). "Quantum Randomness May Not Be Random." New Scientist (online edition). https://www.newscientist.com/article/mg19726485700-quantum-randomness-may-not-berandom/.1034a

24. Arthur, W. (2004). Biased Embryos and Evolution. CCambridge: Cambridge University Press.

25. de Duve, C. (n.d.). $A-Z$ Quotes. https:// www.azquotes.com/quote/730686

26. Morris, S. (2003). Life's Solution: Inevitable Humans in a Lonely Universe. Cambridge: Cambridge University Press.

27. Than, K. (2010). "All Species Evolved From Single Cell, Study Finds." National Geographic News. https://news.nationalgeographic.com/ news/2010/05/100513-science-evolution-darwinsingle-ancestor/

28. Margulis, L. (2006). "The Phylogenetic Tree Topples." American Scientist, 94(3): 194.

29. Damerow, P. (2000). "How Can Discontinuities in Evolution Be Conceptualized?" Culture \& Psychology, 6(2): $\quad$ 155-60. https:// doi.org/10.1177/1354067X0062004.

30. Benton, M. (2003). "Wipeout: The End-Permian Mass Extinction." New Scientist, 178 (2392): 38. http://palaeo.gly.bris.ac.uk/Essays/wipeout/ default.html

31. Chu, J. (2018). "End-Permian Extinction, Which Wiped out Most of Earth's Species, Was Instantaneous in Geological Time." PhysOrg. https://phys.org/news/2018-09-end-permianextinction-earth-species-instantaneous.html.

32. Hoffman, H. (2019). "Permian Extinction Information and Facts." National Geographic. https://www.nationalgeographic.com/science/ prehistoric-world/permian-extinction/.
33. Song, H., et al. (2013). "Two Pulses of Extinction during the Permian-Triassic Crisis | Nature Geoscience." Nature Geoscience, 52: 52-56. https:// www.nature.com/articles/ngeo1649

34. MIT. (2019). "End-Permian Extinction Happened in 60,000 Years-Much Faster than Earlier Estimates, Study Says." PhysOrg. https://phys.org/news/201402-end-permian-extinction-yearsmuch-fasterearlier.html

35. Hlodan, O. (2007). "Macroevolution: Evolution above the Species Level." BioScience, 57(3): 222-25. https://doi.org/10.1641/B570304.

36. Overton, W. and Reese, H. (1981). "Conceptual Prerequisites for an Understanding of Stability-Change and Continuity-Discontinuity." International Journal of Behavioral Development, 4 (1): 99-123. https:// doi.org/10.1177/016502548100400107.

37. Schopf, T. J. M. Ed. (1972). Models in Paleobiology. San Francisco: Freeman, Cooper \& Co.

38. Stanley, S. (1975). "A theory of evolution above the species level." Proceedings of the National Academy of Sciences, 72: 646-650.

39. Pennell, M., Harmon, L., Uyeda, J. (2014). "Is There Room for Punctuated Equilibrium in Macroevolution?" Trends in Ecology \& Evolution, 29 (1): 23-32. https://doi.org/10.1016/ j.tree.2013.07.004.

40. Zhang, X., et al. (2014). "Triggers for the Cambrian Explosion: Hypotheses and Problems." Gondwana Research, 25(3): 896-909. https://doi.org/10.1016/ j.gr.2013.06.001.

41. Dawkins, R. (1990). The Selfish Gene. 2 edition. Oxford: Oxford University Press.

42. Pekkonen, M., Tarmo Ketola, T., T. Laakso, J. (2013). "Resource Availability and Competition Shape the Evolution of Survival and Growth Ability in a Bacterial Community." PLOS ONE, 8(9): e76471. https://doi.org/10.1371/journal.pone.0076471.

43. Drury, J., Clavel, J., Manceau, M., Morlon, H. (2016). "Estimating the Effect of Competition on Trait Evolution Using Maximum Likelihood Inference." Systematic Biology, 65(4): 700-710. https:// 
doi.org/10.1093/sysbio/syw020

44. Gayon, J. (2007). Darwinism's Struggle for Survival: Heredity and the Hypothesis of Natural Selection. 1 edition. Cambridge: Cambridge University Press.

45. Wilson, E. (1975). Sociobiology: The New Synthesis. Cambridge, Mass: Belknap Press.

46. Weintraub, P. (2011). "Wilson's Theory of Altruism Shakes Up Understanding of Evolution." Discover Magazine. http://discovermagazine.com/2011/janfeb/03

47. Boltz, K. (2016). "Cooperation, Not Struggle for Survival, Drives Evolution, Say Researchers: Empirical Experiment Confirms New Hypothesis on Evolution of Life. ScienceDaily. https:// www.sciencedaily.com/ releases/2016/05/160512100708.htm

48. Denison, R., Muller, K. (2016). "The Evolution of Cooperation." The Scientist Magazine. https:// www.the-scientist.com/features/the-evolution-ofcooperation-34284

49. Witkowski, O., Nitschke, G. (2018). "The Dynamics of Cooperation Versus Competition." In Proceedings of the Genetic and Evolutionary Computation Conference Companion. New York: ACM. https:// doi.org/10.1145/3205651.3205688

50. Stewart, J. (2000). Evolution's Arrow: The Direction of Evolution and the Future of Humanity. Canberra: The Chapman Press.

51. Wöhrmann, K., and S. K. Jain, S. Ed. (1990). Population Biology: Ecological and Evolutionary Viewpoints. Berlin, Heidelberg: Springer Berlin Heidelberg.

52. Alley, T. (1982). "Competition Theory, Evolution, and the Concept of an Ecological Niche." Acta Biotheoretica, 31(3): 165-79.

53. Cavanna, A., Nani, A. (2014). Consciousness Theories in Neuroscience and Philosophy of Mind. Berlin: Springer-Verlag.

54. Read, R. (2008). "The 'Hard' Problem of Consciousness Is Continually Reproduced and Made Harder by All Attempts to Solve It." Theory, Culture \& Society, 25(2): 51-86. https:// doi.org/10.1177/0263276407086791
55. Henriques, G. (2013). "Three Worldviews on the Nature of Consciousness." Psychology Today. http://www.psychologytoday.com/blog/theoryknowledge/201303/three-worldviews-the-natureconsciousness- 1

56. Dennett, D. (2017). From Bacteria to Bach and Back: The Evolution of Minds. New York: W. W. Norton \& Company.

57. Blanquet, P. (2011). "Advances In Interdisciplinary Researches to Construct a Theory of Consciousness." Journal of Behavioral and Brain Science, 1(4): 242-61. https://doi.org/10.4236/ jbbs.2011.14031

58. Nuwer, R. (2014). "This Guy Simultaneously Raised a Chimp and a Baby in Exactly the Same Way To See What Would Happen." Smithsonian. https:// www.smithsonianmag.com/smart-news/guysimultaneously-raised-chimp-and-baby-exactly-same -way-see-what-would-happen-180952171/

59. Hayashi, M., Matsuzawa, T. (2003). "Cognitive Development in Object Manipulation by Infant Chimpanzees." Animal Congition, 6: 225-33.

60. Jablonka, E. (2009). "Transgenerational Epigenetic Inheritance: Prevalence, Mechanisms, and Implications for the Study of Heredity and Evolution." Quarterly Review of Biology, 84: $131-36$

61. Jablonka, E., Lamb, M. (2015). "Commentary: Reflections on Jablonka E, Lamb MJ. The Inheritance of Acquired Epigenetic Variations." International Journal of Epidemiology, 44(4): 1103-1105. https://doi.org/10.1093/ije/dyv023

62. Lachmann, M., Jablonka, E. (1996). "The Inheritance of Phenotypes: An Adaptation to Fluctuating Environments." Journal of Theoretical Biology, 181(1): 1-9. https://doi.org/10.1006/ jtbi.1996.0109

63. Burkeman, O. (2010). "Why Everything You've Been Told about Evolution Is Wrong | The Guardian." https://www.theguardian.com/science/2010/ mar/19/evolution-darwin-natural-selection-geneswrong

64. Kofler, N. (2019). "Brain in a Dish, Babies by Design: What It Means to Be Human." Nature: 333-34. 
65. Noble, D. et al. (2014). Journal of Physiology, 592: 2237-2244.

66. Bjorklund, D. (2006). "Mother Knows Best: Epigenetic Inheritance, Maternal Effects, and the Evolution of Human Intelligence." Evolutionary Developmental Psychology, 26(2): 213-42. https:// doi.org/10.1016/j.dr.2006.02.007

67. Pigliucci, M. (2009). "Down with Natural Selection?" Perspectives in Biology and Medicine, 52(1): 134-40.

68. Shkliarevsky, G. (2015). "Squaring the Circle: In Quest for Sustainability." Systems Research and Behavioral Sciences, 32(6): 629-49.

69. Maturana, H. (2002). "Autopoiesis, Structural Coupling and Cognition: A History of These and. Other Notions in the Biology of Cognition." Cybernetics \& Human Knowing, 9(3-4): 5-34.

70. Piaget, J. (1998). The Origins of Intelligence in Children. Madison, Conn.: International Universities Press, Inc.

71. Chardin, P. (1959). The Phenomenon of Man. New York: Harper \& Row, Publishers.

72. Niven, J., Chittka, L. (2016). "Evolving Understanding of Nervous System Evolution." Current Biology, 26.

73. Nei, M. (2007). "The New Mutation Theory of Phenotypic Evolution." Proceedings of the National Academy of Sciences,104(30): 12235-42. https:// doi.org/10.1073/pnas.0703349104

74. Tarlach, G. (2014). "Mutation, Not Natural Selection, Drives Evolution." Discover Magazine. http:// discovermagazine.com/2014/march/12-mutation-not -natural-selection-drives-evolution.

75. Kauffman, S. (1993). The Origins of Order: Self-Organization and Selection in Evolution. New York: Oxford University Press.

76. Vicsek, T. (2002). "The Bigger Picture," Nature, 418: 131.

77. Bailly, F., Longo, G. (2007). "Randomness and Determination in the Interplay Between the Continuum and the Discrete." Mathematical Structures in Computer Science 17(2): 289-305.
Reflexivity." The Philosophical Forum, 44.

79. Editorial. "A Focus on Regulatory RNAs | Nature Cell Biology." Nature Cell Biology, 21: $535 . \quad$ https:// doi.org/10.1038/s41556-019-0325-2

80. Брайчевский, М. (1968). ПОХОДЖЕННЯ РУСI. Київ: Наукова думка.

81. Vijver, G., Salthe, S., and Delpos, M. (2013). Evolutionary Systems: Biological and Epistemological Perspectives on Selection and Self-Organization. Berlin: Springer.

82. Johnson, B., Lam, S. (2010). "Self-Organization, Natural Selection, and Evolution: Cellular Hardware and Genetic Software." BioScience 60(11): 879-85.

83. Campbell, D. (2013). "Downward Causation in Hierarchically Organized Biological Systems." E:CO 15(3): 139-51.

84. Buchanan, M. (2010). "Evolution, but Not as We Know It." New Scientist 205(2744): 34-37.

85. Gayon, J. (2007). Darwinism's Struggle for Survival: Heredity and the Hypothesis of Natural Selection. Cambridge: Cambridge University Press.

86. Dembski, W. (2002). No Free Lunch: Why Specified Complexity Cannot Be Purchased without Intelligence. Lanham: Rowman \& Littlefield Publishers.

87. Dembski, W. (1998). The Design Inference by William A. Dembski. Cambridge England; New York: Cambridge University Press. https:// doi.org/10.1017/CBO9780511570643.

88. Behe, M. (2007). The Edge of Evolution: The Search for the Limits of Darwinism. New York: Free Press.

89. Olofsson, P. (2008). "Probability, Statistics, Evolution, and Intelligent Design." Chance 21(3): 42-45. https:// doi.org/10.1080/09332480.2008.10722917.

90. Rennier, J. (2002). "15 Answers to Creationist Nonsense." Scientific American 287(1): 78-85. https://www.scientificamerican.com/article/15answers-to-creationist/

78. Peters, F. (2013). "Theories of Consciousness as 